Teología y Vida, Vol. LIII (2012), 521-545 | 521

\title{
Derecho internacional y derecho civil: una teoría de acción comunicativa para difundir el evangelio
}

\author{
Hernán Neira \\ UNIVERSIDAD DE SANTIAGO DE CHILE*
}

DERECHO INTERNACIONAL Y DERECHO CIVIL: UNA TEORÍA DE ACCIÓN COMUNICATIVA PARA DIFUNDIR EL EVANGELIO

Hacia 1538, Francisco de Vitoria escribió dos lecciones sobre los indígenas de América: De indis recenter inventis relectio prior (Sobre los indios recientemente descubiertos, relección primera) y De indis sive de iure belli hispanorum in barbaros, relectio posterior (Sobre los indios americanos, o el derecho español a hacer la guerra contra los bárbaros, segunda relección); la primera dedicada a los indios, y la segunda, al derecho de guerra ${ }^{1}$.

Estas lecciones -conocidas como relecciones- fueron dadas de forma solemne y abierta al público una vez por año. En la primera lección,

\footnotetext{
Con el apoyo del Fondo Nacional de Investigación, Ciencia y Tecnología, Chile, proyecto 1085080, titulado La globalización como filosofía de la historia: bases americanas, y de la Universidad de Santiago de Chile. Traducido al castellano por el autor. Fue escrito en inglés como contribución al coloquio internacional Die Normativität des Rechts in der spanischen Spätscholastik, que tuvo lugar en Bad Homburg, organizado por el Excellenzcluster Normative Orders, de la GoetheUniversität Frankfurt am Main, 2009.

1 De ahora en adelante, las dos lecciones serán nombradas como De indis prior y De indis posterior. Sin embargo, De indis prior se divide en dos partes. Dada la variedad de ediciones, con diferentes títulos, paginación y divisiones, hemos tratado de utilizar un criterio universal de referencias, fácil de encontrar en cualquier edición. Para De indis prior, denominamos la parte en números romanos (I, II, etc.); la sección en números arábigos y la página de la edición de la Biblioteca de Autores Cristianos (BAC). Como De indis posterior no está dividido en partes, para este libro damos directamente la sección. Por ejemplo: De indis prior I, 1, p. 648 significa: De indis prior, parte I, sección 1, p. 648 (BAC). De indis posterior 1, p. 816 significa: De indis posterior, sección 1, p. 816 (edición $\mathrm{BAC}$ ).
} 
Francisco de Vitoria afirma que, de acuerdo con el derecho internacional, entonces llamado ius gentium o derecho de gentes, hay una comunidad natural entre todos los seres humanos y, debido a ello, los europeos tienen derecho a predicar el evangelio a través del continente americano y a asegurar ese derecho por medio de la guerra, si fuera necesario ${ }^{2}$. Cuarenta años más tarde, en 1576, en Lima, el jesuita José de Acosta, en De procuranda indorum salut ${ }^{3}$, escribe un informe sobre este derecho. Es una especie de tratado de comunicación, en el que establece cuáles serían los derechos y métodos legítimos para divulgar el evangelio entre los indios, así como los límites de esa acción. Esa discusión, de fondo teológico-filosófica, constituye un tipo de "bisagra» normativa entre el derecho de gentes (ius gentium), que hoy llamaríamos derecho internacional, y el derecho civil (ius civile).

Durante el siglo XVI, la relación jurídica y filosófica entre los indios y los europeos fue vista esencialmente como tema de guerra. La pregunta era: ¿tenían los europeos el derecho a hacerle la guerra a poblaciones con las que acababan de encontrarse? Y ¿̨cuál es el fundamento civil, natural o divino, de la ley o derecho, o de la ausencia de ellos, para llevar a cabo lo que durante el siglo XVI fue llamado evangelización? Afortunadamente, hoy, el pensamiento de varios de los autores que trataron este tema es bien conocido y es fácil acceder a sus escritos, incluso más de lo que en algunos casos se pudo entonces. Ahora bien, nuestro propósito no es tanto examinar el conjunto de su pensamiento, sino examinar cómo en ellos se articulan como un solo asunto el derecho civil, el derecho de gentes y la evangelización.

\section{¿QUÉ SIGNIFICA «EVANGELIZAR»?}

Puesto que la palabra ha adquirido un significado que supera al mundo solamente hispánico, veamos, en primer lugar, qué significa en inglés. El Oxford Concise Dictionary define la palabra como «Predicar el evangelio

2 Francisco de Vitoria, De indis prior, I, 1-3, pp. 648-649.

3 Este título podría traducirse como Sobre la búsqueda de la salvación de los indios, pero normalmente no se traduce al español. José De Acosta, De procuranda indorum salute. Colección Corpus Hispanorum de Pace, edición bilingüe. Ed. Consejo Superior de Investigaciones Científicas, Madrid, 1984 (Vol. XXIII); 1987 (Vol. XXIV). 
(a personas o la abs.); ganar (a una persona) hacia la cristiandad» ${ }^{4}$. Por su parte, la Real Academia Española define esta palabra como «Del lat. cristiano evangelizare. 1. Tr. Predicar la fe de Jesucristo o las virtudes cristianas $»^{5}$. Ambas definiciones son correctas, pero insuficientes, porque evangelizar, en América, durante el siglo XVI, suponía algo mucho más amplio, por las siguientes razones:

Primero: Evangelizar fue un deber que se deriva de la Bula Inter caetera (1493), es decir, de una cesión del papa Alejandro IV a la Corona española, por medio de la cual los reyes de España recibían el derecho a someter al Nuevo Mundo con la finalidad de convertir a la fe católica a los pueblos que allí pudieran encontrar. En razón de la naturaleza de tal cesión, la religión quedaba vinculada y apoyada profundamente al poder político y militar. Más aún, los obispos eran nombrados por la Corona y ningún sacerdote podía viajar a América sin la autorización previa de las autoridades civiles. Los sacerdotes, en los pueblos de indios -donde las autoridades habían concentrado a las poblaciones nativas que vivían dispersas-, eran financiados por los encomenderos y por los «señores de indios». Hasta fines del siglo XVI, en la mayoría de las regiones conquistadas, la evangelización fue precedida o acompañada por el ejército, cuya presencia era necesaria para impedir las revueltas indígenas, para garantizar la participación de los indios en misa, para mantener la seguridad en los caminos y proteger la vida del sacerdote.

Segundo: aunque fuesen poderes distintos, no había separación de la Iglesia y del Estado como se entiende hoy. El bautismo y el matrimonio eran religiosos. La violación de dogmas o el comportamiento considerado anticristiano era investigado por la Inquisición, institución eclesial, pero determinada la culpabilidad, la imposición de la pena correspondía a las autoridades civiles. La Inquisición fue establecida en 1478. Inicialmente se dirigía en contra de los judíos y musulmanes conversos, pero posteriormente también en contra de los protestantes y de la «idolatría» indígena. Atahualpa, rey del Perú, fue condenado en 1533 sobre la base de una acusación político-religiosa. (Se le entregó una Biblia, él la abrió y la arrojó al suelo, porque no pudo escuchar la palabra de Dios; esto es, no logró escuchar voces del libro).

4 «Evangelizar», en Concise Oxford Dictionary. (OUP, Oxford 1980).

5 Real Academia Española, «Evangelizar», [en línea] [fecha de consulta: 9 octubre 2007]. Disponible en http://www.rae.es 
Tercero: Además de las consecuencias religiosas de lo que la Iglesia llamaba la salvación del alma de los indios, la conversión de estos suponía una fuerte contribución a la legitimación del poder de la Corona en América, poder que, al mismo tiempo, era tan necesario para hacer posible la evangelización. Un indígena convertido se transformaba en uno que aceptaba el origen divino del poder de la Corona, lo que no era el caso de otro que permaneciera sin ser convertido. De acuerdo con el derecho de gentes del siglo XVI, no se aceptaba que se sometiera a un indio para obtener por la fuerza su conversión, pero sí se aceptaba que un indígena convertido debiera más obediencia a las autoridades cristianas que a las no cristianas. En América, los objetivos religiosos se reunían con los políticos.

Cuarto: en algunos casos, las naciones indígenas, desde el punto de vista jurídico y político, eran reconocidas como naciones extranjeras. En consecuencia, los pueblos que las habitaban eran sujeto y objeto del ius gentium. Una nación indígena podía ser objeto de la acción internacional, pero esta nación también podía actuar como tal en contra de los intereses españoles, siguiendo las reglas de un sistema internacional incipiente y de acuerdo a las órdenes de sus propias autoridades y al derecho civil. En tales casos, las relaciones entre los españoles y los indígenas eran, también, fruto de una tensión entre el derecho civil y el internacional. Naturalmente, sabemos que, en la práctica, pocas veces las autoridades indígenas fueron consideradas actores del sistema internacional.

Quinto: junto con la estructura político-religiosa, había una estructura privada. Los indios fueron puestos bajo el poder directo y privado de los encomenderos y de los señores de indios. Los encomenderos y los señores de indios eran civiles que actuaban en forma privada y que no representaban el poder político, pero gracias al poder político podían beneficiarse del trabajo indígena forzado, a cambio de lo cual tenían el deber de predicar el evangelio a su costo, intercambio que, en conjunto, se realizaba al interior de las estructuras del poder colonial español.

En América, la evangelización fue una mezcla multifacética de religión y política. Colocar a los indios bajo el poder político de la Corona española y en un lugar subordinado era necesario para alcanzar una finalidad religiosa; alcanzar un propósito religioso contribuía a legitimar la Corona ante los ojos de los indígenas como de los demás poderes europeos, incluyendo al Vaticano, al tiempo que afianzaba el 
lugar subordinado de los indígenas en la estructura laboral. La cesión internacional llevada a cabo mediante la bula Inter caetera es a la vez un asunto de derecho internacional y de derecho canónico. En conjunto, la evangelización constituye un tejido de hechos y significados que hacen de ella algo muy distinto de lo que resultó en otras situaciones, en otros continentes o en otras épocas. Desde el comienzo la evangelización involucró al derecho internacional público (el derecho de gentes), a la ley civil y a la religión, y es una tarea que se realiza sobre la base de una superposición de intereses y tradiciones no siempre coherentes. La evangelización, en América, alude a un complejo que asocia y opone el derecho civil al internacional, como puede constatarse en la mayoría de los teólogos, filósofos y juristas españoles, independientemente de su posición en relación con las referidas guerras. Veamos ahora cómo trabaja este complejo en las concepciones que Francisco de Vitoria y José de Acosta tienen sobre el tema.

\section{Evangelización y COMUNicación SEgún Francisco de Vitoria}

El rico entretejido entre los distintos componentes de la evangelización aparece en todas las obras principales de Francisco de Vitoria. En De indis prior y en De indis posterior, Vitoria considera si es lícito o no bautizar a los niños de los llamados infieles contra la voluntad de sus padres $^{6}$. En pocas palabras, resolver el asunto religioso del bautismo contra la voluntad de los padres requiere resolver, previamente, un asunto de dominio político-jurídico. ¿Comunicar el evangelio ligado al tema de dominio? Sí, y ligado al dominio civil, internacional, público y privado. El asunto se presenta bajo tres «cuestiones»:

«Primera, por qué derecho han venido los bárbaros [barbari] a dominio de los españoles. En la segunda, qué potestad tienen los reyes de España sobre ellos en lo temporal y en lo civil. En la tercera, qué pueden los reyes o la iglesia sobre ellos en lo espiritual y en lo tocante a la religión»?.

Vitoria comienza enunciando que el objeto de esta lección es discutir el asunto del dominio. Hace notar que incluso la Biblia expone muchos ejemplos en los cuales algunos reyes infieles mantienen dominio legíti-

6 Francisco de Vitoria, De indis prior I, 1, p. 642. "An liceat baptizare filios infidelium invitis parentibuss».

7 Francisco de Vitoria, De indis prior I, 1, p. 642. 
mo sobre sus súbditos ${ }^{8}$. Desde el punto de vista de la ley natural y de la ley civil, Vitoria se apoya en la autoridad de Tomás de Aquino y afirma que el dominio se funda tanto en la ley natural como en la ley positiva humana. Y, la ley natural, de acuerdo con el pensamiento escolástico más común, fue dada por Dios a todos, incluso a aquellos que no tienen $\mathrm{fe}^{9}$ o, en sus propias palabras: «el Papa no es señor civil o temporal de todo el orbe, hablando de dominio y potestad civil en sentido propio» ${ }^{10}$. Más adelante explica que «ninguna potestad temporal tiene el Papa sobre aquellos bárbaros ni sobre los demás infieles [...] Aunque los bárbaros no quieran reconocer ningún dominio al Papa, no se puede por ello hacerles la guerra ni ocupares sus bienes» ${ }^{11}$, de forma que no puede obligar a los indios, si no lo desean, a recibir a Cristo o a la fe católica ${ }^{12}$.

Este argumento es, de hecho, la confirmación de otro previo. Basándose en la Biblia, en la primera de las lecciones, titulada Sobre el poder de la Iglesia (De potestate Ecclesiae prior), dada en 1531, Vitoria ya ha afirmado que el Papa no tiene poder temporal sobre las tierras de los infieles, porque solo tiene poder al interior de la Iglesia ${ }^{13}$. Esto también significa que el Papa no puede ceder poder temporal ni tierras a un príncipe. En consecuencia, las palabras donamus, concedimus, et asignamus (damos, concedemos y asignamos) que se usan en la bula Inter caetera con la finalidad de ceder el Nuevo Mundo a los reyes españoles debe ser interpretada de forma limitada y más bien como una cesión con finalidad misionera: la cesión no implica poder político general, sino una autoridad limitada con la finalidad de facilitar la prédica.

Vitoria sigue un procedimiento similar en relación con el poder civil e internacional del emperador y sostiene que los indios tendrían un poder

8 Francisco de Vitoria, De indis prior, I, 7, p. 656.

9 Francisco de Vitoria, De indis prior, I, 7, p. 656.

10 Francisco de Vitoria, De indis prior I, 3, p. 678. «Papa non est dominus civilis aut temporalis totius orbis, loquendo propie de dominio et potestate civili».

11 Francisco de Vitoria, De indis prior I, 1, 642. Ibid., II, 6-7, p. 682. «Papa nullam potestatem temporalem habet in barbaros istos, neque in alios infideles [...] Sequitur colorarium: Quod etiam si barbari noling recognoscere dominium aliquod Papae, non ideo potest eis bellum inferri et bona illorumm occupari».

12 Francisco de Vitoria, De indis posterior, 7, p. 683.

13 Francisco de Vitoria, De potestate Ecclesiae prior. En Francisco de Vitoria, Obras. (BAC, Madrid 1960), 294. 
político legítimo y propio. Incluso si se negaran a aceptar la fe propuesta por los europeos, estos carecerían del derecho a declararles la guerra ${ }^{14}$. Sin embargo, Vitoria propone catorce títulos legítimos bajo los cuales los europeos podrían obtener soberanía sobre los indios. A partir del fundamento común de que en el planeta Tierra existe una «sociedad y comunicación naturales» (naturalis societatis et communicationis) ${ }^{15}$, se sigue:

el derecho a atravesar aquellas provincias indígenas y a permanecer en ellas ${ }^{16}$;

el derecho a comerciar sin daño para los indígenas ${ }^{17}$;

el derecho a propagar [propagandae] y a predicar [predicare] el cristianismo $^{18}$;

el derecho a proteger a los indios que se hayan convertido al cristianismo y que puedan ser forzados por sus autoridades a volver a las religiones anteriores ${ }^{19}$;

el derecho a proteger a los indios que hayan podido ser convertidos por la violencia, pero que después se han vuelto creyentes sinceros ${ }^{20}$; el derecho de evitar las tiranías locales ${ }^{21}$;

el derecho a respetar la voluntad de aquellos indígenas que hayan aceptado voluntariamente la soberanía de la Corona española ${ }^{22}$.

En Sobre la potestad civil, Vitoria establece la diferencia entre el derecho civil (ius gentium) y el derecho internacional (ius gentium). Los reyes, legisladores y pueblos de un solo reino o Estado deben obedecer la ley civil, y no la de otros reinos, mientras que el derecho internacional se aplica al conjunto del orbe y a la relación entre distintos pueblos. En palabras de Vitoria:

«El derecho de gentes no solo tiene fuerza por razón del pacto y convenio de los hombres, sino que tiene fuerza de ley. Y es que el orbe todo,

\footnotetext{
14 Francisco de Vitoria, De indis prior, I, 11, 693.

15 Francisco de Vitoria, II, 1, p. 705.

16 Francisco de Vitoria, 2, p. 705.

17 Francisco de Vitoria, 4, p. 7, 709, 713.

18 Francisco de Vitoria, 9 y 11, pp. 717-718.

19 Francisco de Vitoria, 13, p. 719.

20 Francisco de Vitoria, 14, p. 719.

21 Francisco de Vitoria, 15, p. 720.

22 Francisco de Vitoria, 16, p. 721.
} 
que en cierta manera forma una república universal, tiene poder de dar leyes justas y convenientes para todos [...] de donde se desprende que pecan mortalmente los que violan los derechos de gentes, en la paz o en la guerra [...] Y ninguna nación puede tenerse por no obligada ante el derecho de gentes, porque este ha sido dado por la autoridad de todo el orbe» ${ }^{23}$.

Este derecho de gentes sería una ley natural, y la ley natural es lo que la razón ha establecido ${ }^{24}$, es decir, lo que ha establecido Dios, porque Dios sería su autor ${ }^{25}$. A pesar de esta definición, la mera enumeración de los títulos de soberanía muestra que el derecho de gentes es inseparable del derecho civil. El entretejido de ambas leyes y derechos no ocurre solo en la filosofía de Vitoria, sino en cualquier asunto relativo a la América española. Cualquier intento de separarlos supone la creación de una abstracción, que vuelve imposible entender cómo el dominio europeo fue asegurado en América durante el siglo XVI y cómo fue percibido por los teólogos y filósofos de entonces.

La negación por parte de Vitoria de la soberanía terrenal universal del Papa y del emperador no significa que no les haya sido leales; su lealtad fue reconocida ya en su época, a pesar de que su doctrina se opone a las pretensiones de los encomenderos y de otros autores, como fue el caso de Juan Ginés de Sepúlveda. Carlos V de España encargó a Vitoria asistir al Concilio de Trento en calidad de teólogo imperial, pero para entonces ya estaba enfermo y rechazó el mandato, muriendo ese mismo año (1546). El emperador confiaba en Vitoria del mismo modo que este dudaba en sus lecciones públicas sobre la extensión del dominio y poder de aquel.

Vitoria interpreta restrictivamente la pretensión de poder universal del Papa y del emperador con motivo de la cesión hecha en la bula Inter caetera y la transforma en un poder restringido, pero legal. En nombre del interés de la humanidad o de lo que Vitoria considera una república formada por todo el mundo, el simple someter a otros pueblos se transforma en un sometimiento bajo ciertas condiciones definidas por un poder legal y superior al del emperador y al del Papa; esto es, el derecho de gentes. En el caso de que este derecho fuese violado por los indios, los españoles tendrían autorización para extender su dominio político

23 Francisco de Vitoria, De civile potestate, 21, p. 191.

24 Francisco de Vitoria, De indis prior, I, 2, p. 706.

25 Francisco de Vitoria, De civile potestate, 5-6, pp. 158. 
y declararles la guerra, a condición de que los daños de la guerra sean menores que los daños producidos por la violación del derecho.

Ahora bien, dadas estas restricciones y dado el hecho de que el poder no puede ser impuesto directamente, incluso si es con la finalidad de predicar el evangelio, el primer título para que los españoles ejerzan soberanía sobre los «bárbaros» es la ya mencionada naturalis societatis et communicationis, que se regula por el derecho de gentes. A partir de este título se derivan todos los demás.

Vitoria realiza una breve definición de dicho concepto. Natural, en este caso, significa que se produce en virtud de la ley natural; el derecho de gentes «que es derecho natural o del derecho natural se deriva, según el texto de las Instituciones, de "lo que la razón natural estableció entre todas las gentes" ${ }^{26}$ o lo que ha establecido Dios, que es su autor ${ }^{27}$. Esta sociedad y comunicación naturales se manifestarían en el razonamiento humano. La palabra communicatione se relaciona con communio, que en castellano dan lugar a comunidad y a comunicación, pero Vitoria no desarrolla esta idea, tal vez porque lo considera evidente. La parquedad de las explicaciones de Vitoria sobre la idea de comunicación nos fuerza a considerar este término filosófico en otro autor, que describe lo que esa palabra podía significar en el siglo XVI americano, en el contexto de la ocupación europea del continente.

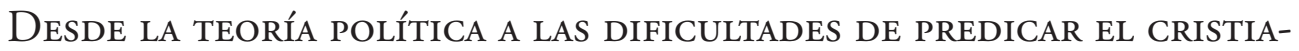
NISMO. José de ACOSTA

Supongamos, entonces, que según los criterios españoles, como los definió Vitoria, no hay violación del derecho de gentes por los indios en la medida en que no han hecho daño injustificado a los españoles. Esto no es solo una suerte de hipótesis, sino que sería un dato comprobado por muchos teólogos y por algunas autoridades europeas de entonces. Por ello mismo, como consecuencia de la llamada Controversia de Valladolid, el Papa decidió que los europeos no tenían derecho de someter a los indios con la finalidad de predicar el cristianismo (independientemente

26 Francisco de Vitoria, De indis prior, I, 2, p. 706. Vitoria cita las Instituciones, título que se da al conjunto de obras del jurista romano Gayo, donde se establece la existencia de un derecho común a todos los seres humanos, aparte del derecho propio de cada pueblo.

27 Francisco de Vitoria, De civile potestate, 5-6, pp. 157-158. 
de si había otros motivos que sí pudieran justificar el dominio). Entonces, no había derecho que pudiera deducirse del derecho de gentes y del derecho civil que permitiese conducir legítimamente a una invasión del continente americano con la intención de predicar. El derecho civil indígena garantizaba a las autoridades nativas su soberanía y su religión propias. Bajo estas condiciones, ¿qué podían hacer los españoles para predicar legalmente el cristianismo a pueblos que lo rechazaban?

La tarea de transformar la idea de una comunicación natural en una guía para la acción y, sobre todo, para la acción de prédica, fue asumida por el jesuita José de Acosta. También conocido como Joseph d'Acosta (o de Acosta), fue misionero, profesor (catedraticum) en la Universidad de Lima y consejero de la Corona. Como Vitoria, Acosta propone una nueva forma de intervención política y religiosa al emperador, hacia quien tampoco puede ser considerado desleal. Su libro De procuranda indorum salute (de ahora en adelante De procuranda) ${ }^{28}$, fue concebido inicialmente como un nuevo catequismo para los jesuitas americanos. Su redacción concluyó hacia 1578, para luego ser presentado al rey Felipe II una década más tarde. En este libro, Acosta desarrolla un juicio moral sobre la colonización y sobre la evangelización, y propone un manual o guía para la prédica bajo restricciones que se derivan de la ley natural y del mandato de Cristo concernientes a la divulgación de su enseñanza por medios pacíficos. Este libro, despojado por la censura de su tono crítico, fue publicado en Salamanca, en 1589. Hoy se conoce la versión completa, que contiene numerosas denuncias de los abusos y de la esclavitud, promovidos en América por funcionarios españoles, encomenderos y sacerdotes. También denuncia allí Acosta el hecho de que, en muchos casos, los indios eran forzados con violencia a aceptar la fe cristiana.

El punto de partida de Acosta es que se ha de buscar un nuevo método para "salvar» a los indios, lo que requiere predicar y obtener la expansión del cristianismo. Entonces convierte la catequesis en un asunto de comunicación y, a diferencia de Vitoria (quien nunca viajó a América), Acosta se ve forzado a ofrecer una comprensión de la comunicación que permita, no imponer el bautismo, sino convertir los indios al cristianis-

28 José de Acosta, De procuranda indorum salute. Colección Corpus Hispanorum de Pace, edición bilingüe. Ed. Consejo Superior de Investigaciones Científicas, Madrid, 1984 (vol. XXIII); 1987 (vol. XXIV). 
mo mediante una aceptación de un acuerdo interior. La consecuencia natural de ello es buscar un cambio de costumbres, porque está convencido de que las costumbres de los indios son contrarias a la religión católica. Cuatro siglos antes de que la comunicación fuera considerada el núcleo de las interacciones sociales por parte de algunos filósofos y sociólogos del siglo XX, Acosta se ve forzado a poner atención en aspectos formales y pragmáticos de las condiciones de la comunicación, en las cuales la acción tiene un papel central. Ya en las primeras líneas de De procuranda, Acosta realiza un resumen de su trabajo y de las dificultades que la prédica encuentra en América:

«Es muy difícil hablar correcta y acertadamente sobre el ministerio de la salvación de los indios. En primer lugar, por ser innumerables estos pueblos de bárbaros y muy diferentes entre sí tanto por el clima, regiones y modo de vestir como por su ingenio, costumbres y tradiciones. Establecer una norma común para adaptarles a todos ellos al Evangelio, educarlos y gobernarlos, cuando se da tanta diferencia de hombres y cosas, definir con propiedad y certeza lo que conviene, requiere grandes dotes, que en modo algunos, a decir verdad, poseemos $\aleph^{29}$.

Acosta resume las dificultades externas del cumplimiento de su deber religioso y político en un capítulo titulado «Los obstáculos principales para la predicación del evangelio entre los indios derivan más bien de los españoles» ${ }^{30}$. Estos obstáculos y dificultades pueden ser clasificados en cinco tipos:

\section{LA Dificultad DEL LENGUAJE}

La primera afirmación de Acosta se refiere a la dificultad de hablar «correctamente» de los indios, debido a su «diversidad». Hablar correctamente sobre ellos, en este caso, se relaciona con el dominio del idioma propio y del idioma indígena. Se trata de una dificultad formal, porque se relaciona con el dominio de las reglas lingüísticas, sin las cuales es

29 Francisco de Vitoria, Proemio, p. 56. «De procuranda salute indorum recte atque apte dicere, perdifficile est. Primum, quod barbarorum gentes innumerabiles sint, ut coelo, locis, habitu, ita ingenio, moribus institutis latissime dissdentes. Quibus omnibus Evangelio conciliandis, instituendis regendisque aliquid commune praecipere, arque in tanto hominum rerumque discrimine accommodate ac certo quid expedit definire, magnae cuiusdam facultatis est, quam profecto nos minime consecuti sumus».

30 Francisco de Vitoria, I, 11, 1, p. 169. 
imposible expresarse y ser comprendido. Esto puede parecer evidente hoy en día, pero no era el caso a mediados del siglo XVI. Por un lado, ni los europeos conocían las lenguas indígenas, ni los indios conocían las europeas, ni había gramática indígena, y la española era relativamente reciente (1492). Esto coloca a la lengua española, como lengua de uso cotidiano, y al latín, como lengua eclesiástica, bajo cierta tensión. La mayoría de los soldados eran iletrados y es posible que muchos sacerdotes, de los escalafones clericales más bajos, no conocieran bien el latín. Algunos sacerdotes celebraban misas que no podían comprender en plenitud y los soldados asistían a una ceremonia que no entendían. El español no tenía palabras adecuadas para comprender muchos aspectos de la vida indígena y los eruditos trataban de superar esta brecha adoptando criterios clásicos para describir lo que la historia y la filosofía clásicas describían como extranjeros o bárbaros ${ }^{31}$.

\section{LA DIFICULTAD DE LA AUSENCIA DE REgLAS COMUNES}

Había una tensión formal entre, por un lado, un catolicismo universal, centralizado y jerárquico, con sus dogmas y métodos únicos para predicar, $y$, por otro, la diversidad indígena. Antes de que el cristianismo pudiera divulgarse en Europa occidental, dicho continente fue invadido por el ejército romano $y$, algunas veces violentamente, otras voluntariamente, unificado culturalmente por quienes acompañaron al ejército, lo que incluía una unificación lingüística por medio del latín. Incluso algunas metáforas propias de Oriente Medio, como la del «cordero de Dios», podían tener alguna referencia visual en Europa, porque el cordero era una animal común en los pastizales de ese continente, pero no era el caso en América. La norma común para predicar en América chocaba con la diversidad de los indios, de sus costumbres, paisajes, lenguas y referencias.

\section{LA DIFICULTAD DE LAS LIMITACIONES PERSONALES DE LOS ESPAÑOLES}

Establecer una regla común para divulgar el evangelio en América requiere "grandes dotes, que en modo alguno, a decir verdad, poseemos" ${ }^{32}$. A diferencia de la arrogancia de la mayoría de los europeos, que insinua-

31 Peter Mason, Deconstructing America: Representations of the Other. (Routledge, London 1990)

32 José de Acosta, De procuranda, Proemio, p. 55. 
ban o afirmaban que las dificultades de predicar en América se debían a una incapacidad natural de los nativos, Acosta reconoce que la incapacidad se funda en los mismos europeos. Los principales impedimentos contra la conversión de los indios son las costumbres de los españoles, especialmente la avaricia y la tiranía ${ }^{33}$. La tarea es demasiado grande en relación con las limitaciones de los sacerdotes.

\section{LA DIFICULTAD DE LOS MALOS MÉTODOS}

Acosta denuncia el uso de la violencia como un método de persuasión: «se ha pretendido persuadir más con la espada que con la palabra, no con inocencia y doctrina de los predicadores, sino con la crueldad y temor de los soldados [...] Me contaba [...] un testigo presencial [...] cómo en este mismo reino, durante la guerra que se hizo contra los incas, se acostumbraba a exponer en la plaza pública a las mujeres colgadas en alto, que sostenía a sus propios bebés, asimismo colgados de sus pechos taladrados, para que en el mismo suplicio las madres estranguladas se vieran obligadas a ser la horca de sus hijos ${ }^{34}$.

\section{LA DIFICULTAD DE LA OPOSICIÓN DE LOS INDIOS}

Acosta está convencido de la superioridad de los españoles y del cristianismo, una superioridad que, sin embargo, no provee a los españoles del derecho a dominar a los indios o a practicar la violencia hacia ellos. A pesar de ello, Acosta afirma que frecuentemente los sacerdotes están "cansados» de su trabajo. Las causas de este cansancio son: "por una parte, la tarea catequética y, por otra, el temperamento natural de los indios [indorum ingenio et natura] $\aleph^{35}$. Además, los indios adoran ídolos y a veces se niegan a confesarse ${ }^{36}$. Pero este desafío, de acuerdo con Acosta, es una parte natural de la prédica y no puede ser un fundamento para la violencia, porque «muchas veces se ha dicho, y muchas veces conviene repetirlo, que la fe no es sino de los que quieren, y que nadie debe hacerse cristiano por la fuerza $»^{37}$.

\footnotetext{
33 José de Acosta, De procuranda, II, 18, 1.

34 José de Acosta, De procuranda, I, 13, 1, p. 193.

35 José de Acosta, De procuranda, IV, 21, 2, p. 159.

36 José de Acosta, De procuranda, V, 10, 1, p. 259.

37 José de Acosta, De procuranda, 2, p. 261
} 
La idea de que el fallo en la divulgación del evangelio en América no se debe a un defecto de los indios, mina el orgullo de aquellos quienes argumentan que, dada la incapacidad de las poblaciones nativas, el único medio para llevarlos a la fe es el sometimiento, con violencia si es necesario. Los obstáculos que encuentra Acosta no son solo externos, porque, dado que el evangelio es universal, no habría un obstáculo interno y absoluto ni en los indígenas ni en el mensaje, es decir, no hay obstáculo absoluto por parte del evangelio mismo. Este podría ser explicado, aunque en términos simples, a cualquiera. En consecuencia, el derecho de gentes y el derecho civil son una base natural y sólida sobre la cual se puede predicar, y ambos se apoyan en una comunidad que proviene del derecho de gentes. Acosta desarrolla una teoría de la catequesis que resuelve estas dificultades externas y, al hacerlo, crea una teoría de la comunicación que sirve de bisagra entre el derecho de gentes, el derecho civil y el derecho canónico.

Comunicando el evangelio: el Derecho de Gentes SE ENCUENTRA CON EL DERECHO CIVIL

El concepto que Acosta tiene de la prédica posee un fundamento triple: un mandato bíblico-teológico de hacer discípulos entre las gentes de todo el mundo ${ }^{38}$; un argumento teológico-filosófico: «no hay raza ninguna de los hombres que esté excluida de la predicación del Evangelio y de la fe ${ }^{39}$, una obligación internacional que se deriva de la bula Inter caetera, y del derecho de gentes y el derecho civil. Hablemos de estos tres aspectos.

De acuerdo con Acosta, los indios se benefician del derecho a ser salvados por medio del evangelio ${ }^{40}$. Este derecho se deriva, no de un argumento teológico, sino del derecho de gentes y del derecho civil, al menos como fueron pensados por él. De acuerdo con el derecho de gentes, la sociedad y comunicación naturales permite la circulación de seres humanos y del evangelio, pacíficamente, alrededor del mundo. Esta ley se asocia con el derecho civil, que obliga a las autoridades locales legítimas a proteger los intereses de sus súbditos. Siguiendo a Vitoria, Acosta acepta la legitimidad de las autoridades indígenas en tanto protejan a sus

\footnotetext{
38 Cf. Mt 28, 20.

39 José de Acosta, De procuranda, I, 1, 1, p. 75.

40 José de Acosta, De procuranda, I, 1, 1, p. 2.
} 
súbditos, porque: «Todo poder público o privado por el cual se administra la república secular, no solo es justo y legítimo, sino que tiene a Dios por autor, de tal suerte, que ni por consentimiento de todo el mundo se puede suprimir ${ }^{41}$.

Sería un deber de las autoridades indígenas permitir la libre circulación de los sacerdotes, y es un deber de las autoridades civiles el permitir a sus súbditos escuchar el evangelio. Esto significa que los españoles no requieren del derecho a sustituir a las autoridades indígenas para alcanzar el objetivo internacional que se deriva de la cesión papal. Esta doctrina se opone directamente a la desarrollada por Sepúlveda en Demócrates segundo y a la realidad con que Acosta se encontraba frecuentemente en Perú: los indios eran sometidos violentamente con la finalidad de alcanzar, en el mejor de los casos, una conversión externa y superficial ${ }^{42}$. La ley civil, cuyo fundamento humano son la razón y la ley natural, intercepta el derecho de gentes en el asunto de la prédica. Ninguna de ambas leyes estaba en el núcleo de las preocupaciones de Acosta, porque su interés y preocupaciones son religiosas. Sin embargo, la doctrina de Acosta de realizar una prédica pacífica se ubica entre el derecho de gentes y el derecho civil. El primero le garantiza el derecho a predicar dondequiera que desee. El segundo, le obliga a respetar las autoridades locales, civiles y religiosas. El mandamiento bíblico y papal solo pueden ser cumplidos en el espacio generado por ambas leyes, que también sirven de límite al poder eclesiástico e internacional: «la infidelidad no es causa justa [de hacer la guerra a los indios], porque solo Dios es juez y vengador de ella. [...] No tiene la iglesia derecho ni poder moral sobre los infieles, si no sobre aquellos únicamente que han entrado en el redil de Cristo por la puerta del bautismo» ${ }^{43}$.

Más aún, en el propósito religioso está el mantener una relación pacífica entre los seres humanos, como propone el derecho de gentes, y es incompatible con la violencia: «Nada se opone tanto a la recepción de la fe como todo lo que sea fuerza y violencia. Pues la fe no puede ser sino vo-

41 Francisco de Vitoria; De potestate civili, op. cit., cap. 1, p. 151. "Omnis, seu publica seu privata potestas, qua respublica saecularis administratur, non solum iusta et legitima est, sed ita Deum auctorem habet, ut net orbis totius consensus tolli aut abrogari posit».

42 José de Acosta, De procuranda IV, 3, 3.

43 José de Acosta, De procuranda, II, 2, 2-3, pp. 255-257. 
luntaria [...] Por tanto, como obedecer por la fe al Evangelio es algo voluntario y libre para todo el mundo y una fe arrancada a la fuerza no puede ser sino demoníaca, al oyente hay que guiarlo con dulzura y benevolencia» ${ }^{44}$.

En consecuencia, para Acosta, el punto de partida de la comunicación legal del evangelio, en la segunda mitad del siglo XVI, implica una conciliación del derecho de gentes y del derecho civil, que él supone basados en la ley natural y divina. Esto solo se puede conseguir mediante el atraer a los indios al evangelio y obteniendo su acuerdo sincero para que abandonen sus creencias y costumbres previas. Pero ¿qué significa "predicar» (predicare)? En el libro I, capítulo 1, en el que exhorta a no desesperar sobre la salvación de los indios, Acosta escribe que «no hay raza ninguna de hombres que esté excluida de la predicación y del Evangelio y de la fe», pero los traductores transforman «communicatione» en "predicación» ${ }^{45}$. Communicatione, como hemos visto, se relaciona con communio, comunidad, y también con la idea de Vitoria de una sociedad y comunicación natural entre la especie humana.

De acuerdo con el derecho de gentes y con el derecho civil, la realización del ideal de conversión, con las limitaciones complementarias del derecho canónico, requiere un acuerdo interior por parte de los indios, lo que es muy diferente del conseguir su sometimiento político. Alcanzar este acuerdo, que se basa en la voluntad de los indios, tiene dos aspectos: por un lado, la conciencia; y, por el otro, un resultado práctico, porque el conocimiento (cognitio) y el deseo o voluntad (appetitio) son dos lados de la racionalidad natural (rationalis naturae) ${ }^{46}$. A partir de esta doble comprensión de la naturaleza humana racional surge un doble método de evangelización: enseñar y exhortar. Los resultados de ambos métodos deben ser un incremento del conocimiento indígena de Cristo y el comienzo de la acción de ellos del actuar con caridad hacia Dios y hacia los demás seres humanos. En el pensamiento católico, la caridad

44 José De Acosta, De procuranda, I, 13, 3, p. 197. «Nihil ita fidei susceptioni adversatur atque vis omnis et violentia. Non enim est fides nisi violentium [...] Quoniam ergo voluntarium est ac liberum cuique obedire Evangelio credendo, neque fides per vim extorta aliorum potest esse quam daemnum».

45 José De Acosta, De procuranda, I, 1, 1, p. 75. «Neque enim genus aliquod hominum exclusum est in Evangelii fideique communicatione, ubi a Christo Domino Apostoli audiunt».

46 José de Acosta, De procuranda, V, I, 3. 
se refleja en el comportamiento. El éxito en la prédica debe tener por resultado en los indios un nuevo conocimiento de Cristo y una decisión voluntaria de modificar comportamientos.

Acosta propone que, para que los indios se vuelvan cristianos, deben resolverse previamente varios aspectos que coinciden con algunos planteamientos contemporáneos de teoría de comunicación, entendiendo por ella un acuerdo para la acción, como lo hace Habermas en la Teoría de la acción comunicativa. Allí expone que esta

«Se refiere a la interacción de a lo menos dos sujetos capaces de lenguaje y de acción que [...] entablan una relación interpersonal. Los actores buscan entenderse sobre una situación de acción para poder así coordinar de común acuerdo sus planes de acción [...] El concepto aquí central, el de interpretación, se refiere primeramente a la negociación de definiciones de la situación susceptibles de consenso " ${ }^{47}$.

Sin embargo, en el caso de la prédica, el acuerdo no es racional, en el sentido moderno del término. El cambio del tipo de acción que busca Acosta se basa más en la fe que en la razón; más en los sentimientos que en argumentos racionales; más en los instrumentos que atraigan a las emociones que en instrumentos para convencer al intelecto. A pesar de estas diferencias, la teoría de la acción comunicativa contemporánea y la teoría de la comunicación de Acosta comparten el hecho de rechazar la violencia y se basan en un supuesto metafísico: una naturaleza humana común, que en el primer caso se basa en la idea de que hay una razón común y, en el otro, en que los seres humanos comparten la naturaleza común de ser hijos de Dios. Toda teoría es hija de su tiempo; una teoría escolástica de la comunicación probablemente deba tener por centro la fe; y una teoría postilustrada probablemente deba estar centrada en la razón, pero en ambas permanece una idea de universalidad, de inspiración metafísica, que permite alcanzar una acción común y prohíbe la violencia.

Para Acosta, una prédica exitosa del evangelio debe tener por resultado un cambio en la fe y en la acción, lo que es fruto de valores que él cree universales. Solo pueden ser forzados por la violencia la expresión externa de valores y fe, pero una fe y valores auténticos suponen la sinceridad. Si estas condiciones no se dan, la prédica falla.

47 Jürgen Habermas, Teoría de la acción comunicativa I. Racionalidad de la acción social y racionalización social (Taurus, Madrid 2001), 124 (versión de Manuel JiméneZ Redondo). 
Pero la ausencia de violencia no solo es una condición requerida por la «legalidad» de la prédica; también es una necesidad pragmática. El contenido del significado solo puede ser debidamente comprendido cuando los requerimientos lingüísticos (conocer las lenguas indígenas) y otras condiciones pragmáticas han sido satisfechas: «El que desconoce el idioma no puede enseñar ni predicar [predicare] la fe» ${ }^{48}$. Es más, los que pretendan divulgar la fe deben ser un ejemplo viviente de ella: «No hay mayor ni más segura esperanza de la salvación de los indios que el ejemplo intachable del buen pastor ${ }^{49}$.

La importancia de estas condiciones pragmáticas obliga a tomar en cuenta lo que hoy se llama las condiciones de recepción, que son tan esenciales para la comunicación como el dominio del lenguaje. La caridad ayuda a que el mensaje penetre en la mente de los indios. De esta manera, la caridad o benevolencia no es una condición externa o superflua, sino una necesidad que debe ser satisfecha con la finalidad de obtener el objetivo. No basta con predicar el evangelio; es aún más importante entender y tomar en cuenta las condiciones bajo las cuales puede ser aceptado. Esto contribuye a comprender que la naturaleza del evangelio hace imposible que pueda ser transmitido por medios exclusivamente intelectuales. Se requiere métodos complementarios y distintos.

\section{Razón NATURAL Y RAZÓN ILUSTRADA}

Asumir que no se puede forzar un cambio de valores y de fe implica el reconocimiento de que el tiempo es un medio necesario para conseguir el objetivo de la evangelización. La velocidad de la historia humana es diferente en cada pueblo. Para Acosta, el evangelio solo puede alcanzar naciones lejanas "gradualmente y a sus tiempos, de acuerdo con la determinación de los designios eternos»" ${ }^{50}$, y es necesario confiar que, con el tiempo, los indios abandonarán sus costumbres y adquirirán otras nuevas $^{51}$. El tiempo, en este caso, no es un enemigo, como podría suponer un punto de vista impaciente, sino un colaborador de la prédica. Cuando la ocupación militar de casi todo el continente estaba ya lograda

\footnotetext{
José de Acosta, De procuranda, IV, 7, 1, p. 55.

49 José de Acosta, De procuranda, IV, 7, 1, p. 129.

50 José de Acosta, De procuranda, I, 2, 2, pp. 85-87.

51 José de Acosta, De procuranda, VI, 24, 1, p. 489.
} 
(1570), Acosta afirma que la evangelización ha alcanzado únicamente cambios forzados y superficiales, y en territorios restringidos. Al introducir el tiempo como parte del proceso de evangelización, Acosta insinúa incorporar el tiempo para la evolución de las mentes y culturas, más lento que el de las armas y la política. La prédica solo puede alcanzar su potencial cuando hay tiempo para la comunicación y para un acuerdo. Bajo esas circunstancias, ser impaciente equivale a optar por la guerra como medio de alcanzar el objetivo religioso, lo que sería contrario a la finalidad y método del cristianismo. En este caso, la guerra viola el derecho de gentes en un doble sentido: porque los indios tienen derecho a estar equivocados en materia religiosa y porque los aleja de la posibilidad de tener contacto con lo que Acosta considera la verdadera religión. Y, de acuerdo con la teo-filosofía de Acosta, el derecho al contacto libre con la verdadera religión es parte del derecho de gentes.

La teoría actual de la acción y de la comunicación ayuda a comprender los propósitos y métodos de Acosta. El fundamento racional de la concepción actual de la comunicación puede, sin embargo, convertirse en una barrera para comprender la amplitud, complejidad y dificultades de la comunicación en un contexto distinto del nuestro y de aquel de la pos-Ilustración europea. La comunicación en una sociedad como aquella del siglo XVI, no centrada en la razón, puede ser considerada legítimamente comunicación según criterios actuales, al menos en cuanto tenga capacidad para crear acuerdos sin hacer uso de la coerción física o mental. Esta razón natural, que en el pensamiento escolástico es reflejo de la voluntad divina, tiene influencia en toda la humanidad al crear una sociedad y comunicación naturales, como hemos visto anteriormente. Con motivo de aquel principio, no requiere de un desarrollo histórico o dialéctico para llegar a su plenitud, pues ha sido establecida en totalidad por Dios desde el comienzo. A diferencia del concepto de razón natural, una razón que tenga un desarrollo por oposición argumentativa del tipo de la de disputatio escolástica, cuyas bases fueron establecidas por Platón en La república, al proponer que el método filosófico es dialéctico, es, puramente racional y separada de todo componente sensible ${ }^{52}$, algo muy distinto de lo requerido para la prédica. En cambio, la comunicación, en el sentido de Acosta, debe ser sensible a la temporalidad y a las con-

52 Platón; La república (Centro de Estudios Políticos y Constitucionales, Madrid 2006), 511. 
diciones en que se da, especialmente cuando la apreciación del mensaje suprarracional y sobrenatural del evangelio depende del momento y condiciones de recepción. Con motivo de ello, la capacidad intelectual potencialmente limitada de algunos indígenas no les impide participar en la comunidad y en la comunicación, incluso si no son capaces de comprender el mensaje por medio de un raciocinio dialéctico o argumental. Sabemos que en la mayoría de los casos los jesuitas intentaron atraer a los indios hacia el cristianismo por medios pacíficos y por medio de la utilización de instrumentos como la caridad o el arte religioso, manteniéndolos en grandes localidades rurales llamadas misiones, alejadas de la influencia directa de los encomenderos y de otros funcionarios, lo que contribuyó a dar lugar a lo que se ha llamado el estilo barroco americano. La Ilustración y la post-Ilustración declararon, demasiado pronto, que aquellos métodos eran irracionales. Esta perspectiva, demasiado estrecha, es incapaz de comprender lo que pueda haber sido uno de los mayores desafíos comunicativos que haya encarado la humanidad en los últimos milenios. Para resolverlo, algunos españoles necesitaron desarrollar cualidades que no eran racionales, en el sentido moderno, sino morales y estéticas, como propone Acosta.

«Pero dirás: se trata de hombres ineptos, rudos, estúpidos, viejos y decrépitos [...] a estos y sus semejantes los va [el sacerdote] a obligar a aprender el misterio de la Trinidad, que es tan difícil aun para los de grande y agudo ingenio? [...] Mi respuesta personal es que el misterio de Cristo [...] no obligo a comprenderlo a nadie, porque eso es de pocos; pero digo que deben creerlo todos, y eso lo pueden todos. Nadie es tan inepto que no pueda pensar de algún modo en Dios y en el hombre [...] No creo que haya nadie que no pueda comprender estas cosas, si se las enseñan debidamente. Se las puede pensar con imágenes corporales [corporali imaginatione], lo cual es muy fácil a los hombres, y se las puede pintar y expresar con palabras» ${ }^{53}$.

Este método estético (imágenes corporales) no es ilustrado y menos postilustrado. Se basa en la comprensión de la razón más como un vínculo común entre los seres humanos que como un medio para alcanzar objetivos. Se puede no compartir el punto de vista de Acosta, según el cual los indios deben abandonar su religión, los indios convertidos ser gobernados por príncipes cristianos y que esos mismos príncipes puedan vengar

53 José De Acosta, De procuranda, V, 4, 8-9, p. 219. 
las ofensas al cristianismo ${ }^{54}$. Sin embargo, la falta de valores compartidos entre europeos e indígenas no impide que, bajo una estructura política que entreteje el poder profano y el eclesiástico, Acosta proponga un método de evangelización que, visto desde el presente, oscila entre lo que se llama acción comunicativa y acción estratégica. El método de Acosta es comunicativo, porque busca un acuerdo válido entre dos comunidades que, inicialmente, no comparten ni valores, ni orientaciones ni acciones; y es estratégico, porque no siempre discute con los indios el contenido e implicaciones de la conversión que él busca ni tampoco discute siempre el hecho de que busca obtener poder sobre los indios, aunque sea solo un poder religioso. Una acción estratégica última utiliza el conocimiento de los valores de los demás como un medio para obtener un fin, que es el propio, y que no es compartido por la comunidad, cuyos valores conoce.

Para apreciar el sentido comunicativo real, aunque al mismo tiempo limitado, de la propuesta de Acosta, es importante mostrar que la traducción de la palabra latina communicatione por la palabra española predicación, o por la palabra inglesa preaching, no es suficientemente exacta y en parte elimina su contenido original, que implica el ser parte de una comunidad, algo que no se logra solo por argumentos intelectuales. El pensamiento de Acosta no es contemplativo (ni tampoco el de los jesuitas), y busca cambios prácticos. El significado de «razón» y de «racionalidad», en la época de Acosta, no es el mismo que lo que se deriva de la tradición kantiano-hegeliana, y que en algunos aspectos será compartido por Marx, Weber y Habermas. Si se aplica a la acción, la razón, en la época de la Ilustración y post-Ilustración, consiste en establecer cuáles son los instrumentos adecuados para alcanzar un fin. En relación con la comunicación, se apoya en la dialéctica para alcanzar acuerdo sobre ciertos valores y normas: «la razón es el actuar según fines», escribe Hegel en la introducción a la Fenomenología del espiritu ${ }^{55}$.

La idea postescolástica de razón natural no es el equivalente al de la idea de razón moderna. No puede «racionalizar» la acción, porque la acción ya estaría regulada por la razón, y no requiere acuerdo sobre valores, porque se supone que Dios ha creado al ser humano con los mismos valores esenciales, que no se requiere discutir, sino aplicar. Más aún, de

54 José de Acosta, De procuranda, I, 2, 3-5, pp. 391-397.

55 Georg Wilhelm Friedrich Hegel, Phänomenologie des Geistes. (Felix Meiner, Hamburg 1954), 22: "Die Vernunft das zweckmäßige Tun ist». 
acuerdo con la idea postescolástica de ley y de razón, la evangelización se basa en un poder sobrenatural, cuyo significado sobrepasa la razón. Con motivo de ello, la idea de comunicación propuesta por Acosta tiene un alcance limitado. Para él, la razón natural es una regla común al interior de la humanidad y es la verdadera base de la comunidad humana y de la comunicación. Dado que existiría una comunidad básica y natural, es posible concebir los asuntos religiosos a partir de «imágenes corporales», sin necesidad de argumentar. Comprender las complejas relaciones entre el pensamiento postescolástico y los indios americanos requiere comprender previamente la idea postescolástica de razón natural y cómo difiere de la idea moderna de razón.

\section{EL TIEMPO DE LA ACCIÓN}

No hay filosofía ni teoría de la comunicación despojadas de supuestos metafísicos y políticos. Esta es la base no declarada de la comunicación sobre la cual puede desarrollarse el acuerdo o el desacuerdo. La teoría de la comunicación natural al interior de la humanidad tuvo muchas versiones en el mundo académico hispánico; algunas de sus figuras más notables fueron Las Casas, Vitoria y Acosta. Sin embargo, la teoría de la comunicación de Acosta estuvo muy lejos de poder impedir las crueldades que fueron informadas por tantos testigos, algunas de las cuales pueden haberse fundado en la idea de esta comunicación natural básica. Incluso, hay algunas argumentaciones de Acosta que sugieren que su doctrina puede haber conducido a un incremento de la opresión de los indígenas bajo el pretexto de convertirlos, protegerlos o salvarlos, aspectos que no hemos desarrollado aquí y que se encuentran especialmente en el libro IV y V de De procuranda ${ }^{56}$. Eso requiere un juicio moral y político que, hoy, no podemos ni se puede evitar, pero que no es nuestro tema aquí.

La lectura de De procuranda ayuda a comprender que, durante el siglo XVI, los asuntos americanos pusieron a la filosofía, a la teología y a la política bajo tensión, y que toda argumentación sobre ellos tenía consecuencias inmediatas sobre el destino de millones de seres humanos. Estas consecuencias se deben al inseparable entretejido de ideas e intereses civiles, internacionales y eclesiásticos. Las decisiones tenían que ser tomadas demasiado de prisa en relación con el tiempo que la filosofía tenía

\footnotetext{
56 José de Acosta, De procuranda, IV, 19; y V, 9-11.
} 
para agotar la exploración de estos temas; retrasarse un día significaba extender un día el sufrimiento de miles de personas o simplemente quitarles la vida a muchos indígenas. Pocas veces en la historia la filosofía, o más bien la teo-filosofía, ha sido tan importante en el destino de tantos pueblos. Contrariamente a muchos de los debates filosóficos contemporáneos, la mayoría de los debates en que participaron Las Casas, Vitoria o Acosta tuvieron una consecuencia inmediata y no solo filosófica. No era un debate racional, en el sentido contemporáneo de la palabra racional, era un debate lleno de pasión y cargado de intereses, donde la exhortación y el requisitorio eran más frecuentes que la tradicional disputatio escolástica, incluso si, a veces, aquellos autores argumentaron manteniendo la forma externa de la disputatio medieval. Este debate buscó tanto convertir a los indios como adquirir algún poder sobre ellos, con la finalidad de cumplir lo que los autores consideraban un mandato divino, una orden eclesiástica o una obligación internacional, como la emanada de la bula Inter caetera. El tiempo de la acción y el tiempo en el cual la filosofía debía transformar el mundo entró en la historia ya durante el siglo XVI, tres siglos antes de la undécima tesis sobre Feuerbach, donde Marx declara que la tarea del filósofo no es más interpretar el mundo, sino cambiarlo. Y, de hecho, esto es una prueba complementaria de que incluso las filosofías aparentemente más abstractas siempre han estado profundamente ancladas en los intereses de su época.

A pesar de las limitaciones del pensamiento teo-filosófico, la teoría de Acosta muestra lo lejos que puede llegar la idea de Vitoria de una comunicación natural entre los seres humanos cuando se aplica a la prédica del evangelio, bajo las condiciones muy particulares de la América de mediados del siglo XVI. Hoy tenemos acceso a muchos testimonios de cuán violenta culturalmente fue en muchos casos la aplicación del modelo de comunicación pacífica de Vitoria y de Acosta. Puede haber contribuido a privar a los indígenas de sus recursos inmateriales, a pesar de lo benevolente que hayan podido ser dichos modelos. Cuando estos modelos se asociaron con la opresión laboral o política, la consecuencia fue una rápida pérdida de las capacidades culturales y estéticas ${ }^{57}, \mathrm{y}$, a veces, la destrucción física de los indios.

57 Serge Gruzinski, La colonización de lo imaginario. Sociedades indígenas y occidentalización en el México español. Siglos XVI-XVIll (Fondo de Cultura Económica, México D. F. 1991). 
A pesar de ello, es filosóficamente fascinante tratar un debate que ocurrió hace cuatro siglos y que plantea tantos desafíos a la filosofía contemporánea y especialmente a la filosofía de la acción. Estos desafíos incluyen el encontrar un modo de coexistencia pacífica de muchas religiones en un mismo país o incluso en el mundo; la migración de millones de personas; el choque entre, por un lado, la racionalidad y el comportamiento occidental, y, por el otro, la mentalidad tradicional en tantos países; el declinar del liderazgo pacífico de las democracias occidentales en el mundo; y el surgimiento de nuevos liderazgos internacionales, incluidas las organizaciones criminales de carácter político y no político.

Abordar los desafíos planteados por los conflictos de normas y leyes en los comienzos del debate académico español sobre los indios y pueblos americanos muestra la necesidad de mantener cierta modestia en relación con nuestras capacidades y pretensiones de imponer criterios de acción propios como criterios universales, pero también muestra que la acción es necesaria, tal vez tanto como durante el siglo XVI en América. 
Resumen: En Los indios recién descubiertos (1538), Francisco de Vitoria afirma que hay una comunicación y sociedad natural entre todos los seres humanos. Cuarenta años después, en Lima, el jesuita José de Acosta, en Sobre la salvación de los indios (1576), escribe una suerte de informe sobre cómo poner en práctica esta comunicación por medio de métodos pacíficos de predicación. Es un tipo de tratado de comunicación, en el cual denuncia la práctica de las conversiones forzadas. Para Acosta, el éxito de la comunicación del evangelio a los indios supone un cambio voluntario de creencias y acciones, basado en lo que él considera la razón natural. Esta discusión filosófica y teológica muestra que hay un entretejido normativo entre el ius gentium, ius civile y ley eclesiástica, y que la actual teoría de la comunicación tiene mucho que aprender de este caso paradigmático y parcialmente fracasado de comunicación del evangelio en América.

Palabras clave: Francisco de Vitoria, José de Acosta, teoría de la comunicación, ius gentium, indios americanos, razón natural

Abstract: In On the Recently Discovered American Indians (1538), Francisco de Vitoria states that there is natural communication and society among all human beings. Forty years later, in Lima, the Jesuit José de Acosta, in On the Salvation of the Indians (1576), writes a report about how to put into practice this communication through peaceful preaching. It is a kind of communication treatise, in which he also denounces the practice of forcing conversions. To Acosta, successful communication of the gospel to Indians signifies a willing shift of beliefs and actions, based on what he considers natural reason. This philosophical and theological discussion shows that there is a normative interweaving between ius gentium, ius civile and ecclesiastic law, and that a contemporary theory of communication has a lot to learn from the paradigmatic and partially failed case of communicating the gospel in America.

Keywords: Francisco de Vitoria, José de Acosta, communication theory, ius gentium, American Indians, natural reason 